\title{
Sublingual Gland Carcinoma
}

National Cancer Institute

\section{Source}

National Cancer Institute. Sublingual Gland Carcinoma. NCI Thesaurus. Code C8397.

A carcinoma that arises from the sublingual gland. Representative examples include cystadenocarcinoma and mucoepidermoid carcinoma. 